УДК 327.8

РОДИОНОВ Владимир Александрович - доктор политических наук, заведующий кафедрой истории и регионоведения стран Азии Бурятского государственного университета им. Доржи Банзарова (670000, Россия, Республика Бурятия, г. Улан-Удэ, ул. Ранжурова,6а; vladimir_198025@таil.ru)

\title{
РОССИЙСКИЕ РЕСУРСЫ «МЯГКОЙ СИЛЫ» В МОНГОЛИИ: ТЕКУЩЕЕ СОСТОЯНИЕ И ПОТЕНЦИАЛ ИСПОЛЬЗОВАНИЯ
}

\begin{abstract}
Аннотация. В статье анализируется политика «мягкой силы» России в отношении Монголии. Наряду с политическими, экономическими, военными методами воздействия, не менее важными остаются культурные, связанные с русским языком, образованием, наукой, массовой информацией. Россия, обладая сравнительно большим ресурсным потенциалом для использования «мягкой силы» в Монголии, в основном унаследованным от эпохи социализма, на данный момент не проводит адекватную ему политику. Основная причина заключается в отсутствии российских НПО, способных проводить политику «мягкой силы» в Монголии.
\end{abstract}

Ключевые слова: Россия, Монголия, «мягкая сила», русский язык, образование

Д аже самый поверхностный анализ текущей внешнеполитической деятельности России на монгольском направлении позволяет сделать один главный и в целом неутешительный вывод. Все попытки российской стороны увеличить свое присутствие (прежде всего в экономической сфере) в Монголии, как правило, заканчиваются неудачей, что заставляет задуматься о причинах подобного положения вещей и способах изменения ситуации в лучшую для России сторону.

Принимая во внимание высочайшую степень конкуренции, развернувшейся в современной мировой политике, многие авторы констатируют активное использование государствами различных форм, методов и инструментов, объединяемых общей категорией «мягкая сила» (soft power). Вслед за родоначальником данного понятия Дж. Наем-младшим, мы видим в ней прежде всего «способность добиваться желаемых результатов на основе добровольного участия, симпатии и привлекательности» [Nye 2004]. Конкретизируя функциональное назначение этого явления, можно сказать, что речь идет в т.ч. о формировании и культивировании в стране-объекте влияния общественного мнения, отвечающего интересам страны - субъекта влияния.

Институционализация «мягкой силы» в России произошла в 2010-х гг, когда упоминание этого понятия в официальных документах и выступлениях государственных лиц стало нормой. В действующей Концепции внешней политики РФ, утвержденной 30 ноября 2016 г., указано, что «неотъемлемой составляющей современной международной политики становится использование для решения внешнеполитических задач инструментов “мягкой силы”, прежде всего возможностей гражданского общества, информационно-коммуникационных, гуманитарных и других методов и технологий, в дополнение к традиционным дипломатическим методам» 1 . О важности «мягкой силы» для российской

\footnotetext{
1 Концепция внешней политики Российской Федерации (утв. Президентом РФ 30.11.2016). Доступ: https://www.mid.ru/foreign_policy/official_documents/-/asset_publisher/CptICkB6BZ29/ content/id/2542248 (проверено 29.01.2020).
} 
внешней политики неоднократно говорил президент В.В. Путин ${ }^{1}$, министр иностранных дел С.В. Лавров. В частности, глава МИДа во время одной из пресс-конференций заявил: «Более широкое задействование так называемой мягкой силы будет способствовать повышению практической эффективности внешней политики России» ${ }^{2}$. Помимо развития идейно-политического дискурса, реализация «мягкой силы» требует наличия институциональных структур, представленных государственными и негосударственными организациями. В современной России можно отметить ряд подобных организаций (например, Россотрудничество, фонд «Русский мир», Фонд поддержки публичной дипломатии им. А.М. Горчакова), которые в основу своей деятельности включают распространение российского культурного влияния за рубежом, используя широкую палитру методов «мягкой силы». В целом, общий настрой на использование «мягкой силы» во взаимоотношениях с зарубежными партнерами, а также соответствующее институциональное сопровождение являются частью внешнеполитической стратегии России.

Однако общая стратегия не тождественна конкретному сценарию/алгоритму действий по отношению к той или иной стране - объекту влияния. Что именно и как применять в отношениях со страной - объектом влияния является одним из главных вопросов в рамках стратегии применения «мягкой силы». С.К. Песцов и А.М. Бобыло выделяют 3 основных элемента формулы «мягкой силы»: ресурсы, привлекательность и желаемое поведение, объединяемые между собой производством привлекательности и производством желаемого поведения [Песцов, Бобыло 2015: 111]. А.П. Ворочков, изучая публичную дипломатию как проявление «мягкой силы», указывает на технологии, ресурсы, институциональных участников и эффект, при помощи которых возможен анализ данного феномена [Ворочков 2016: 55]. Учитывая многоаспектность темы российского влияния в современной Монголии, в настоящей статье основное внимание будет сосредоточено на состоянии ресурсной и институциональной базы «мягкой силы» России в ее отношениях с монгольской стороной.

В начале 1990-х гг. была открыта новая страница в истории отношений России и Монголии. Стремясь укрепить добрососедские отношения с Россией и Китаем и развить партнерские связи с внерегиональными державами, Монголия отказалась от членства в каких-либо военно-политических союзах и сделала ставку на многоопорную внешнюю политику. В результате впервые за многие десятилетия монгольская территория перестала рассматриваться в качестве арены потенциального военного противостояния великих держав. Данные изменения стали предпосылкой для принципиально новой международно-политической ситуации вокруг Монголии, характеризующейся невоенным соперничеством великих держав за влияние в регионе. Конкурентная среда, созданная под влиянием многоопорной внешней политики Улан-Батора, заставляет основных игроков, включая Россию, активно использовать методы «мягкой силы».

Однако возможности для применения российской «мягкой силы» были существенно лимитированы последствиями постсоциалистической трансформации. Наряду с резким сокращением торгово-экономических связей, значительно сократилось российско-монгольское сотрудничество в сфере образования, науки, культуры. На взгляд монгольской исследовательницы А. Нямдолжин, сфера гуманитарных связей «в наибольшей степени пострадала в результате

\footnotetext{
1 Путин назвал русский язык «мягкой силой». - РИА Новости. 05.11.2019. Доступ: https://ria. ru/20191105/1560601120.html (проверено 23.02.2020).

2 Лавров: Россия продолжит политику «мягкой силы». - РИА Новости. 23.01.2013. Доступ: https://ria.ru/20130123/919370016.html (проверено 23.02.2020).
} 
произошедших перемен» [Нямдолжин 2016: 39]. В связи с этим главным лейтмотивом стратегии «мягкой силы» России в Монголии в начале XXI в. стала тема восстановления/возрождения ранее наработанных связей.

По общему мнению, образ страны можно считать центральной частью «мягкой силы». Согласно данным социологических опросов, ежегодно проводимых известным фондом Монголии «Сант Марал», Россия воспринимается как самый желанный зарубежный партнер Монголии, а отношения с россиянами видятся монголам как наиболее комфортные. Можно сказать, что у России в этом плане существенное преимущество перед другими государствами, имеющими свои интересы в Монголии.

Таблица 1

Какая страна является лучшим партнером для Монголии? (\%)*

\begin{tabular}{|l|c|c|c|c|c|c|c|}
\hline \multicolumn{1}{|c|}{ Годы } & $\mathbf{2 0 1 3}$ & $\mathbf{2 0 1 4}$ & $\mathbf{2 0 1 5}$ & $\mathbf{2 0 1 6}$ & $\mathbf{2 0 1 7}$ & $\mathbf{2 0 1 8}$ & $\mathbf{2 0 1 9}$ \\
\hline Россия & 51,1 & 53,3 & 59,0 & 61,1 & 66,6 & 69,8 & 70,0 \\
\hline Китай & 0,7 & 1,2 & 1,3 & 1,6 & 0,6 & 0,8 & 2,4 \\
\hline Южная Корея & 1,2 & 1,9 & 0,7 & 1,6 & 0,9 & 2,4 & 4,0 \\
\hline США & 8,2 & 7,6 & 6,5 & 6,8 & 6,5 & 6,3 & 5,6 \\
\hline Япония & 7,0 & 4,8 & 7,0 & 6,3 & 7,3 & 5,9 & 7,3 \\
\hline ЕС и Великобритания & 4,0 & 2,8 & 2,3 & 4,0 & 1,6 & 1,3 & 4,6 \\
\hline
\end{tabular}

* Politbarometer. - Sant Maral Foundation. Доступ: https://www.santmaral.org/publications (проверено 23.02.2020).

Таблица 2

С гражданами какой страны монголы лучше общаются и сотрудничают? (\%)*

\begin{tabular}{|l|c|c|c|c|c|c|c|}
\hline \multicolumn{1}{|c|}{ Годы } & $\mathbf{2 0 1 3}$ & $\mathbf{2 0 1 4}$ & $\mathbf{2 0 1 5}$ & $\mathbf{2 0 1 6}$ & $\mathbf{2 0 1 7}$ & $\mathbf{2 0 1 8}$ & $\mathbf{2 0 1 9}$ \\
\hline Россия & 24,6 & 25,4 & 31,3 & 38,7 & 32,1 & 42,5 & 34,0 \\
\hline Китай & 14,1 & 14,5 & 10,8 & 10,7 & 13,6 & 9,8 & 11,3 \\
\hline Южная Корея & 8,8 & 10,7 & 7,1 & 13,9 & 17,8 & 19,0 & 30,7 \\
\hline США & 5,4 & 2,7 & 2,3 & 1,6 & 1,9 & 1,8 & 3,3 \\
\hline Япония & 6,8 & 4,5 & 6,2 & 4,5 & 6,2 & 7,3 & 5,4 \\
\hline ЕС и Великобритания & 2,2 & 1,5 & 1,2 & 1,2 & 0,8 & 0,8 & 2,1 \\
\hline
\end{tabular}

* Politbarometer. - Sant Maral Foundation. Доступ: https://www.santmaral.org/publications (проверено 23.02.2020).

Пытаясь понять причины положительного образа России, необходимо обратиться прежде всего к истории отношений между странами в эпоху социализма, когда СССР воспринимался в Монголии как самый надежный союзник и друг монгольского народа, образно - «старший брат», т.е. моральный авторитет. И хотя с тех пор роль России в отношениях с Монголией кардинально изменилась, для многих монголов (особенно старшего и среднего поколения) наша страна по-прежнему ассоциируется с самыми позитивными страницами своей истории. Отсюда можно заключить, что образ России в Монголии - это не только (а возможно, и не столько) результат деятельности российских субъектов «мягкой силы», но и ресурс, доставшийся со времен социализма.

Организаторы социологических опросов не показывают поколенческий срез 
полученных результатов. Однако, судя по общему высокому проценту положительных оценок России и россиян, монгольская молодежь также в массе своей позитивно настроена в отношении нашей страны. В связи с этим можно предположить, что для молодого поколения монголов, в основном не владеющих русским языком и не заставших эпоху социализма, положительный образ России определен не столько социалистическим прошлым, сколько текущими геополитическими установками. Суть этих установок сводится к тому, что северный сосед видится естественным (прежде всего, военным) противовесом Китаю как главному источнику вызовов и угроз национальной безопасности страны, что также можно отнести к исторически обусловленному образу России.

В связи с этим логичными выглядят усилия российских организаций, ведущих свою деятельность в Монголии, по актуализации в общественном сознании монголов таких значимых исторических событий, как совместная победа в боях на реке Халхин-Гол и в освободительной войне 1945 г., большая роль России в становлении независимости Монгольского государства, развитии его экономики, социальной сферы, науки и образования. Достаточно вспомнить серию торжественных мероприятий, проведенных в 2019 г. в честь 80-летия победы на Халхин-Голе, кульминацией которых стал визит в Монголию президента России В.В. Путина. Вместе с тем, как отмечает В.И. Терентьев, многие подобные мероприятия плохо рекламируются, проводятся в первую очередь для официальных лиц и тех монголов, которые различным образом связаны с Россией, в то время как рядовые граждане Монголии мало представлены на таких мероприятиях [Терентьев 2018: 46]. В результате эффект оказывается незначительным.

В социалистический период важнейшим ресурсом советского влияния в Монголии был русский язык. Как указывает известный английский монголовед К. Хамфри, «в социалистический период широкие слои населения Монголии узнавали о современном мире по большей части из русско-советской учебной и художественной литературы» [Хамфри 2012: 15]. Монгольский исследователь Г. Томтогтох, характеризуя роль русского языка в истории Монголии XX в., образно называет его «единственным окном в мир» для монголов [Томтогтох 2015: 209]. С 1950-х гг. во всех общеобразовательных школах Монголии с 5-го класса русский язык стал обязательным предметом [Свердлова, Энхбаатар 2015: 35]. О глубине проникновения русского языка в монгольское общество свидетельствуют данные Международной ассоциации преподавателей русского языка и литературы. К началу 1990-х гг. 67,5\% монголов читали и понимали по-русски, 45\% - писали, 44,8\% - понимали, 33,7\% - говорили [Фалилеева и др. 2013: 14]. Практически вся управленческая и интеллектуальная элита социалистической Монголии свободно владела русским языком, а сам язык носил неофициальный статус второго государственного. Однако за последние три десятилетия русский язык утерял свои былые позиции в Монголии. Сокращение экономических, научно-образовательных, культурных связей между Россией и Монголией на фоне расширения контактов со странами Запада и Востока снизило ценность и практическую значимость русского языка в глазах монгольского общества. С 2002 г. обязательным для изучения в монгольских школах стал английский. Русский язык, в свою очередь, вошел в число факультативных предметов наряду с другими иностранными языками.

Несмотря на негативную тенденцию сокращения пространства русского языка в Монголии, определенный интерес к нему остался в силу сохраняющихся торгово-экономических связей, активизировавшегося в последние годы научного и образовательного сотрудничества. Помимо этого, среди факторов 
потенциального увеличения числа изучающих русский язык также можно выделить:

1) остающееся значительное число людей, владеющих в различной степени русским языком, в организационном плане объединенных Монгольской ассоциацией преподавателей русского языка (МонАПРЯЛ);

2) увеличившиеся за последнее время в связи отменой визового режима повседневные контакты между русскими и монголами;

3) наличие общего для обоих языков алфавита - кириллицы.

Так, в 2006 г. Министерство образования, науки и культуры Монголии приняло решение об обязательном преподавании русского языка (по 2 часа в неделю) в 7-9 классах средних образовательных школ. Начиная с 2016/2017 уч. года русский язык в средней школе преподают в 10-12 классах как обязательную дисциплину ${ }^{1}$. Чтобы понять эффективность подобных нововведений, необходимо рассмотреть состояние институциональной базы для изучения и популяризации русского языка в современной Монголии.

Обучение русскому языку происходит на нескольких образовательных уровнях, начиная с ряда детских садов и ясельных групп и продолжая средними общеобразовательными школами. Несмотря на формальное возвращение русского языка в школьную систему Монголии, условия для его преподавания не отвечают методическим требованиям. В частности, учебники содержат фактические, грамматические и стилистические ошибки, ощущается острая нехватка учителей русского языка, большая часть которых относится к старшему поколению [Терентьев 2017: 58]. В Монголии, главным образом в Улан-Баторе, насчитывается 12 школ с преподаванием на русском языке [Томтогтох 2015: 211]. Однако все подобные школы берут плату за обучение, что не всегда по карману средней монгольской семье. В результате малоимущие слои населения, в т.ч. из сельской местности, лишены возможности получить качественное образование на русском языке.

Важными проводниками русского языка в Монголии являются Российский центр науки и культуры (РЦНК), входящий в структуру федерального агентства «Россотрудничество», а также русские центры фонда «Русский мир», при которых действуют обучающие языковые курсы. С сентября 2009 г. при поддержке фонда «Русский мир» в Свято-Троицком приходе Улан-Батора действует Русский детский культурный центр, предоставляющий детям из малообеспеченных семей возможность бесплатно изучать русский язык ${ }^{2}$.

Важнейшей задачей на данный момент является повышение мотивации монгольских граждан для изучения русского языка, в т.ч. посредством развития интереса к получению высшего образования российского образца.

Высшее образование является ресурсом, тесно связанным с распространением русского языка и российской культуры. В период с 1922 по 1991 г. в вузах СССР получили образование около 55 тыс. монгольских граждан [Россия и Монголия... 2011: 287]. В 1990-х гг. многие монголы переориентировались на получение высшего образования в ЕС, США, Южной Корее, Японии, Австралии. Отдельное место в этом ряду занял Китай, ежегодно предоставляющий около 1000 квот для обучения монгольских граждан за счет китайской стороны.

Как и в случае с русским языком, престиж российского высшего образования, несмотря на некоторое снижение в начале постсоциалистического пери-

\footnotetext{
1 Мунхцэцэг Б. Русский язык в Монголии угасает при отсутствии политических усилий. ИА REGNUM. 31.08.2016. Доступ: https://regnum.ru/news/polit/2173654.html (проверено 23.02.2020).

2 В столице Монголии при Свято-Троицком приходе открылся Русский детский культурный центр. Доступ: https://mospat.ru/ru/2009/10/21/news6803/ (проверено 23.02.2020).
} 
ода, сохранился на довольно высоком уровне. К факторам, поддерживающим заинтересованность монголов в получении российского высшего образования, можно отнести следующие. Во-первых, в Монголии по-прежнему функционирует созданная в социалистическую эпоху инфраструктура, технологически основывающаяся на советских/российских стандартах. Обслуживание и периодическое обновление данных технологически сложных объектов требует соответствующих специалистов, подготовка которых возможна только в России. Во-вторых, наработанные за годы социализма академические и образовательные связи, в т.ч. через систему совместных научно-исследовательских экспедиций, также не могли полностью исчезнуть. В-третьих, российское образование с точки зрения соотношения «стоимость обучения / качество образования», по мнению исследователей, в наибольшей степени соответствует уровню доходов средней монгольской семьи [Фалилеева и др. 2013: 12]. Наконец, не последнюю роль играет фактор влияния старшего поколения монголов на умонастроения своих молодых соотечественников. Показательны в этом смысле слова генерального секретаря МонАПРЯЛ С. Эрдэнэмаама: «У нас в стране все еще есть огромное количество людей, получивших образование в России, в бывшем Советском Союзе, в странах СНГ. Они-то знают, что такое российское образование, что такое русский язык, что такое русский человек, что есть русский характер и т.д. Они, их дети и внуки просто не могут не тяготеть к этому великому языку» 1 .

Основными каналами вовлечения монгольских граждан в систему российского высшего образования являются их обучение в вузах России и коммерческое присутствие в Монголии через систему филиалов.

В 2017-2018 гг. в вузах России обучались около 2200 монгольских студентов 2 . В последние годы российская сторона постепенно увеличивает число мест в вузах страны для обучения граждан Монголии за счет бюджета, что влечет за собой общее увеличение числа монгольских студентов в России, способствует определенной популяризации отечественного высшего образования, а следовательно улучшает образ нашей страны среди молодых монголов.

Таблица 3

Динамика численности квот для монгольских студентов в российских вузах*

\begin{tabular}{|c|c|}
\hline Учебные годы & Число мест \\
\hline $1999 / 2000$ & 130 \\
\hline $2000 / 2001$ & 150 \\
\hline $2004 / 2005$ & 200 \\
\hline $2009 / 2010$ & 230 \\
\hline $2010 / 2011$ & 270 \\
\hline $2011 / 2012$ & 300 \\
\hline $2014 / 2015$ & 383 \\
\hline $2017 / 2018$ & 450 \\
\hline $2018 / 2019$ & 500 \\
\hline
\end{tabular}

* Образование в России для иностранцев. Доступ: https://studyinrussia.ru/ (проверено 29.01.2020).

1 Мунхцэцэг Б. Русский язык в Монголии угасает при отсутствии политических усилий. Доступ: https://regnum.ru/news/polit/2173654.html (проверено 23.02.2020).

2 Российский статистический ежегодник: 2018. статистический сборник. М.: Росстат. 2018. C. 201 . 
В то же время в системе предоставления квот существуют проблемы. По информации главного специалиста Министерства образования и науки РФ Т. Соболевой, многие из приезжающих в российские вузы монгольских студентов предъявляют аттестаты об окончании российской школы в Улан-Баторе, но при этом совершенно не говорят по-русски. Проверки показывают значительное число подделок предоставляемых школьных аттестатов. Это приводит к большому проценту отчислений монголов из российских вузов, что негативно сказывается на общем имидже российского высшего образования и подрывает эффективность системы выделения квот ${ }^{1}$. Кроме того, многие монголы, получившие российские дипломы, возвращаясь домой, не в состоянии трудоустроиться, что определяется отсутствием соответствующих их профессиям рабочих мест и других условий [Терентьев 2018: 47].

Одним из потенциально перспективных направлений для улучшения качества отбора монгольских абитуриентов является запланированное открытие в Монголии центра довузовской подготовки. Так, в конце 2019 г. между российской и монгольской стороной было подписано соглашение о создании подобного центра, преподавать в котором будут специалисты ведущих российских университетов. Наряду с прочими предметами предполагается преподавание русского языка ${ }^{2}$.

Пессимистично выглядит и ситуация с филиалами российских вузов в Монголии. В течение последних 10 лет наблюдается устойчивая тенденция сокращения их числа в Монголии. По состоянию на конец 2019 г. в Монголии реально осуществлял свою деятельность только филиал РЭУ им. Г.В. Плеханова при том, что еще в конце нулевых годов действовали по меньшей мере 6 филиалов российских вузов [Россия и Монголия... 2011: 275]. К основным причинам подобного положения дел можно отнести слабое взаимодействие между филиалами в плане координации деятельности, их недостаточную материальную и кадровую базу, жесткую конкуренцию со стороны других иностранных вузов в Монголии. Отдельно стоит отметить практическое отсутствие финансовой и иной поддержки филиалов российских вузов в Монголии со стороны российского частного бизнеса.

Каналом наращивания российского влияния в Монголии могли бы стать различные СМИ, способные транслировать на монгольскую аудиторию привлекательный образ России и задавать выгодную российской стороне повестку. В условиях сокращающегося пространства русского языка в Монголии наличие российских монголоязычных каналов информации стало бы существенным подспорьем в деле продвижения социокультурного влияния России. К сожалению, на данный момент в Монголии нет ни одного представительства российских СМИ, способных предоставлять альтернативную западным массмедиа информацию о России и мире. В 2013 г. прекратила свое вещание на Монголию радиостанция «Голос России - монгольская редакция» ${ }^{3}$. Спустя некоторое время перестал работать русскоязычный телеканал «АИСТ-Монголия». $R T$ и Sputnik, флагманы российской информационной политики, располагающие внушительной зарубежной аудиторией, не имеют специального отдела по Монголии, их сайты не располагают версией на монгольском языке. В результате такие важные для отношений между странами события, как безвозмездная

\footnotetext{
${ }^{1}$ Монгольские родители покупают детям места в вузах РФ. - Новости России и Мира. 10.02.2012. Доступ: https://st-news.info/mongolskie_roditeli_pokupayut_detyam_mesta_v_vuzah_rf.html (проверено 23.02.2020).

2 Россия намерена создать 50 центров довузовской подготовки за рубежом к 2024 году. - TACC. 25.11.2019. Доступ: https://tass.ru/obschestvo/7196145 (проверено 23.02.2020).

3 «Голос России» умолк в Монголии. Доступ: http://zabinfo.ru/108741 (проверено 23.02.2020).
} 
передача российской стороной военной техники и совместные военные учения, предоставление крупной партии вакцин для монгольского скота, оказание гуманитарной помощи в случаях стихийных бедствий, остаются вне поля зрения широкого круга общественности Монголии либо подаются монгольскими СМИ сухо и буднично.

Помимо указанных выше проблем и ограничений российской политики «мягкой силы» в Монголии, необходимо указать на следующее. Деятельность таких институтов, как посольство РФ в Монголии, РЦНК, фонд «Русский мир», при всей их важности и результативности, имеет свои ограничения в плане продвижения российских интересов в социокультурной сфере.

Во-первых, все эти структуры являются государственными организациями и напрямую ассоциируются с политикой Российского государства. Это, в свою очередь, нередко порождает недоверие среди граждан Монголии, опасающихся подпадания страны под иностранное влияние. Кроме того, по этой же причине российские институты «мягкой силы» становятся удобными мишенями для критики со стороны различных НПО (правозащитных, религиозных, экологических и пр.), ориентированных на Запад, Японию или Южную Корею. В связи с этим важнейшей задачей в рамках стратегии «мягкой силы» в Монголии является увеличение участия российских НПО, способных продвигать интересы России без формальной привязки к государственным структурам.

Во-вторых, практика последних лет показывает, что отечественные институты нацелены на работу в основном с узким кругом лиц (официальными представителями властей, бизнесменами, деятелями культуры и науки, российскими соотечественниками, постоянно проживающими в Монголии). Этого явно недостаточно, если речь идет о такой задаче, как формирование общественного мнения и привлечение на свою сторону широких масс населения. Говоря иначе, «высокая» «мягкая сила», нацеленная на работу с элитой, должна идти рука об руку с «низкой», т.е. работой с массами.

Статья выполнена при финансовой поддержке РФФИв рамках научно-исследовательского проекта РФФИ-Министерства культуры, образования, науки и спорта Монголии «"Мягкая сила” в российско-монгольских отношениях: сравнительный анализ», проект № 19-514-44001.

\section{Список литературы}

Ворочков А.П. 2016. Институты реализации «мягкой силы» в современной России - Вестник Марийского государственного университета. Сер. Исторические науки. Юридические науки. № 2(6). С. 53-59.

Нямдолжин А. 2016. Монголо-российские отношения на современном этапе (1990-2004 гг.). Улаанбаатар.

Песцов С.К., Бобыло А.М. 2015. «Мягкая сила» в мировой политике: проблема операционализации теоретического концепта. - Вестник Томского государственного университета. Сер. История. № 2. С. 108-114.

Россия и Монголия на пути стратегического партнерства. 2011. М.: ИВ РАН, Институт международных исследований АН Монголии. 440 с.

Свердлова Н.А., Энхбаатар У. 2015. Русский язык: история и перспективы изучения в Монголии. - Magister Dixit. Научно-педагогический журнал Восточной Сибири. № 2(18). С. 34-40.

Терентьев В.И. 2017. Русский язык в Монголии сегодня. - Азия и Африка сегодня. № 9. С. 56-60. 
Терентьев В.И. 2018. Россия и россияне глазами современных монголов. Азия и Африка сегодня. № 10. С. 45-50.

Томтогтох Г. 2015. Русский язык в социокультурном пространстве современной Монголии. - Лингвистика и межкультурная коммуникация. № 4(18). С. 208-213.

Хамфри К. 2012. Русский язык как средство взаимоотношения между Монголией и Россией в XX - начале XXI века. - Русский язык в постсоветском мире: уход и возвращение? Oпыт Монголии: материалы международной научнопрактической конференции. Улаанбаатар, 15-16 сентября 2010 г. Улаанбаатар. C. 13-18.

Фалилеева Н.В., Филин С.А., Дугаржав Л., Ерофеева И.А. 2013. Проблемы взаимодействия России и Монголии в сфере образования. - Приоритеть России. № 12(201). С. 10-22.

Nye J. 2004. Soft Power: The Means to Success in World Politics. N.Y.: PublicAffairs. $192 \mathrm{p}$.

RODIONOV Vladimir Aleksandrovich, Dr.Sci. (Pol.Sci.), Head of the Chair of Asian History and Regional Studies, Banzarov Buryat State University (6a Ranzhurova St, Ulan-Ude, Republic of Buryatia, Russia, 670000; vladimir_198025@ mail.ru)

\title{
RUSSIAN SOFT POWER RESOURCES IN MONGOLIA: CURRENT STATUS AND USAGE POTENTIAL
}

\begin{abstract}
The article analyzes the policy of soft power of Russia towards Mongolia. Along with political, economic, and military methods of influence, cultural ones related to the Russian language, education, science, and mass information remain equally important. Russia has relatively large resources for using soft power in Mongolia, mainly inherited from the era of socialism. However, it does not currently pursue an adequate policy for resources. The main reason of it is the lack of Russian NGOs capable of conducting the policy of soft power in Mongolia. The main channels of soft power of the Russian Federation in Mongolia are the spread of the Russian language, the involvement of Mongolian citizens in the system of Russian higher education. Various media could become a channel for increasing Russian influence in Mongolia, capable of broadcasting an attractive image of Russia to the Mongolian audience and setting the agenda favorable to the Russian side. Keywords: Russia, Mongolia, soft power, Russian language, education
\end{abstract}

